\title{
Meiotic drive in the sex chromosome system of the varying lemming, Dicrostonyx torquatus Pall. (Rodentia, Microtinae)
}

\author{
Emily A. Gileva
}

Institute of Plant and Animal Ecology, Urals Scientific Center, Academy of Sciences of the U.S.S.R., 202, 8 March Street, Sverdlovsk, 620008, U.S.S.R.

\begin{abstract}
In the varying lemming, numerous fertile $\mathrm{XY}$ females occur regularly due to the $\mathrm{X}$-linked mutation $\left(\mathrm{X}^{*}\right)$. Their frequency both in natural populations and laboratory colonies turned out to be about twice higher than that expected under random segregation of heterochromosomes in both sexes. It has been shown in experiments that an excess of XY females resulted from a preferential segregation of the $\mathrm{Y}$ chromosome in males. Segregation distortion is not produced by selective embryonal mortality. Meiotic drive of the $\mathrm{Y}$ chromosome also causes a significant decrease of sex ratio. Although in the varying lemming meiotic drive is rather weak (the segregation ratio of the $Y$ being $0 \cdot 54-0 \cdot 59$ ), it seems to contribute essentially to the evolutionary spread and the maintenance of the $X^{*}$ mutation in populations. The example of Dicrostonyx and probably of other microtines also demonstrates the possible role of meiotic drive in the regulation of the population sex ratio in mammals.
\end{abstract}

\section{INTRODUCTION}

Meiotic drive (segregation distortion) has been suggested as an evolutionary force. A driven allele or a driven chromosome, may increase in frequency even when deleterious. Thus, meiotic drive may create a basis for inadaptive evolution (Sandler and Novitski, 1957). Apparently it can be regarded as a manifestation of selfishness of DNA.

Originally meiotic drive was defined as being a deviation from Mendelian segregation ratio in heterozygotes resulting exclusively from a disturbance in the mechanics of meiosis. Later the term became applied to a broader range of phenomena including transmission anomalies where the causal connection with meiosis was not very evident (Levontin, 1967; Zimmering et al., 1970). In such cases it would be more correct perhaps to speak of segregation distortion rather than "meiotic drive", but the term is in common usage, so in the present paper it will be applied (in its broad sense) equally with the term "segregation distortion".

It is not yet clear how often the phenomenon in question takes place in natural populations. Because of its rare occurrence, some authors are prone to be sceptical about the evolutionary importance of meiotic drive (e.g., Snyder, 1982). Indeed, there are not many well-established examples of meiotic drive that are known. However, it seems reasonable to believe that its frequency is underestimated due to several causes.

First, the cases where the driven element has attained fixation are not detectable.

Second, a conspicuous marker is needed to discern initially the segregation distortion (tailless mice as in the $T-t$ system of Mus musculus, eyecolour as in SD-Drosophila, knob-bearing chromosome as in maize, etc.). In the absence of such a marker meiotic drive may easily stay unregistered.

Third, it is noteworthy that practically all species in which meiotic drive has been unequivocally substantiated are well-known genetic and/or laboratory models. That is hardly accidental. Evidently a laboratory breeding analysis is required as an essential condition for revealing segregation distortion. For the overwhelming majority of species the condition is difficult to realise, if not impossible. Meanwhile the possibility of performing extensive breeding experiments can be of crucial importance especially when the deviation from Mendelian ratio is small.

Hence many a case of meiotic drive, primarily the moderate ones, might have escaped the 
researchers' attention. So every newly revealed instance of regular segregation distortion should be reported, even when its genetic basis is not quite clear. Such is the case with the varying lemming, Dicrostonyx torquatus, presented in this paper. Meiotic drive acts here in an unusual chromosome system of sex determination which has been described earlier (Gileva and Chebotar, 1979; Gileva, 1980). This system (with some modification) was found in many Palaearctic and Nearctic populations of the varying lemming (Rausch and Rausch, 1972; Kozlovsky, 1974; Gileva, 1983; Jarrell, 1985). A similar mechanism has been discovered in the wood lemming, Myopus schisticolor (Fredga et al., 1976). Briefly the system can be delineated as follows.

Only some of the females (64 per cent in our experimental colonies) possess a conventional sex chromosome constitution, XX. The other fertile and phenotypically normal females exhibit a male karyotype but in these females, as in all males, the $Y$ chromosome as a separate member of the complement is absent. It follows from the genetic and cytological analyses that in D.t.chionopaes from Yakutia the male determinant is located on the autosome No. 5 which is homologous to the long arm of the X, and in D.t.torquatus it is situated on the autosome produced by translocating chromosome No. 5 on to chromosome No. 18. The male determinant is either the cytologically undetectable part of the $Y$ translocated on to the autosome, or it is the autosomal gene(s). The second supposition appears to be less probable but it cannot be excluded until the mechanism of sex determination in mammals is fully elucidated. It should be noted in this connection that in D.t.chionopaes from Chukotkan region cytological manifestation of the Y-autosomal translocation are entirely absent. So in earlier publications we were referring to the sex chromosome condition of males and females with a masculine karyotype as XO. Carothers (1980) and Bull and Bulmer (1981) criticised our nomenclature pointing out that the sex chromosome system in the varying lemming corresponded exactly to White's "neo-X-neo-Y" mechanism (White, 1978). Therefore, these authors denominated the males and the aberrant females of the varying lemming as $\mathrm{XY}$. This is acceptable as regards D.t.torquatus and D.t.chionopaes from Yakutia but not D.t.chionopaes from Chukotka. As the latter is not dealt with in the present paper, the $\mathrm{XX} / \mathrm{XY}$ nomenclature will be used.

The XY females of the varying lemming occur due to the mutant genetic factor located most probably on the $\mathrm{X}$ chromosome. The mutant $\mathrm{X}$ chromosome which induces the development of $\mathrm{XY}$ specimens as females will be referred to as $\mathrm{X}^{*}$, and its homologue of the wild type as $X^{0}$. The symbol $X$ is used for either of them, especially when the genotype is unknown. The pattern of inheritance of sex chromosomes in the varying lemming is given in scheme 1. This scheme of inheritance was substantiated by extensive breeding experiments accompanied by a cytological analysis (Gileva and Chebotar, 1979).

If the segregation of sex chromosomes in males and all types of females is random and no selective prenatal loss occurs, the secondary sex ratio and the proportion of $X Y$ daughters in the progeny of females with genotypes $X^{0} X^{0}, X^{*} X^{0}$ and $X^{*} Y$ must be as shown in scheme 1 . Our initial analysis showed, as it seemed, that the results of experimental crosses within two laboratory stocks were in concordance with the theoretical values (Gileva and Chebotar, 1979; Gileva et al., 1980). Such a concordance became dubious after Bull and Bulmer (1981) worked out elaborate formulae for equilibrium genotype frequencies and compared the frequencies expected under equal fertilities of the three female genotypes and under random segregation of sex chromosomes with those observed in laboratory and natural populations of $D$. torquatus. It was shown that the sex ratio (proportion of males) was lower and the frequency of $\mathrm{XY}$ females was higher than the theoretical estimates. So the hypothesis of equal fertility of diverse female genotypes and the assumption of sex chromosomes segregating randomly might not be true. To clear this matter out, the present author's previous experimental data will be reinvestigated here and new findings mainly concerned with segregation distortion will be added.

\section{MATERIALS AND METHODS}

The analysis is based on the results obtained in two laboratory colonies of the varying lemming, D. t. torquatus (the Polar Urals) and D. t. chionopaes (the Laptev Sea coast, Yakutia). In females with diverse genotypes sex ratio of offspring (proportion of males), proportion of XY daughters and reproductive parameters were determined. Data on two colonies were combined, as they proved to be homogenous. Animals were sexed firstly at birth and finally at weaning (on day 18-20 after birth). Karyotyping was performed mostly at 3 months of age.

$\mathrm{X}^{*} \mathrm{Y}$ females were recognised cytologically. In previous analysis (Gileva and Chebotar, 1979; 
Scheme 1 Inheritance of sex chromosomes in the varying lemming

\begin{tabular}{|c|c|c|c|c|c|c|c|}
\hline & $\begin{array}{l}\text { Females } \\
\text { Soma }\end{array}$ & $\mathrm{X}^{0} \mathrm{X}^{0}$ & & $X^{*} X^{0}$ & & $\mathrm{X}^{*} \mathrm{Y}$ & \\
\hline & Soma Gametes & $\mathrm{X}^{0}$ & $\mathrm{X}^{0}$ & $\mathrm{X}^{*}$ & $\mathrm{X}^{0}$ & $\mathrm{X}^{*}$ & $\mathrm{Y}$ \\
\hline \multirow[t]{2}{*}{ Males } & $\mathrm{X}^{0}$ & $\begin{array}{l}\mathrm{X}^{0} \mathrm{X}^{0} \\
q\end{array}$ & $\begin{array}{l}\mathrm{X}^{0} \mathrm{X}^{0} \\
q\end{array}$ & $\begin{array}{l}X^{*} X^{0} \\
q\end{array}$ & $\begin{array}{l}\mathrm{X}^{0} \mathrm{X}^{0} \\
q\end{array}$ & $\begin{array}{l}X^{*} X^{0} \\
q\end{array}$ & $\begin{array}{l}\mathrm{X}^{0} \mathrm{Y} \\
\delta\end{array}$ \\
\hline & $\mathrm{Y}$ & $\begin{array}{l}\mathrm{X}^{0} \mathrm{Y} \\
\delta^{*}\end{array}$ & $\begin{array}{l}X^{0} Y \\
0\end{array}$ & $\begin{array}{l}\mathrm{X}^{*} \mathrm{Y} \\
q\end{array}$ & $\begin{array}{l}\mathrm{X}^{0} \mathrm{Y} \\
\delta\end{array}$ & $\begin{array}{l}X^{*} Y \\
q\end{array}$ & $\begin{array}{l}\text { YY } \\
\text { unviable }\end{array}$ \\
\hline $\begin{array}{l}\text { Secondary sex } \\
\text { ratio }\end{array}$ & & 0.500 & & $0 \cdot 250$ & & $0 \cdot 333$ & \\
\hline $\begin{array}{l}\text { Proportion of } \\
\text { XY daughters }\end{array}$ & & 0.000 & & 0.333 & & 0.500 & \\
\hline
\end{tabular}

Gileva et al., 1982) $\mathrm{X}^{0} \mathrm{X}^{0}$ females were distinguished from the $X^{*} X^{0}$ ones by the absence of $X Y$ daughters in the progeny of the former, if a XX dam gave birth to not less than 8 daughters karyotyped. If an XX female had at least one XY daughter, she was classified as an $\mathrm{X}^{*} \mathrm{X}^{0}$ one. As Bull and Bulmer pointed out, such an approach could bring about a certain upward bias in the estimates of the fertility of XX genotypes and of the frequency of $\mathrm{XY}$ daughters in $\mathrm{X}^{*} \mathrm{X}^{0}$ females. Aiming to liquidate this bias and regarding the scheme of inheritance of $\mathrm{X}^{*}$ and $\mathrm{X}^{0}$ as verified, the method of classifying $\mathrm{XX}$ females was modified. It can be seen from scheme 1 that $X^{0} X^{0}$ dams can bear only $X^{0} X^{0}$ daughters and that all $X X$ daughters of $X^{*} Y$ females belong to the $X^{*} X^{0}$ type. So all the $X X$ females of any generation which descended from the original $\mathrm{X}^{0} \mathrm{X}^{0}$ dams have been included into the $\mathrm{X}^{0} \mathrm{X}^{0}$ group, even when less than 8 daughters with two $X$ were found among their progeny. Such an approach is corroborated by the fact that in the 2nd-10th generations obtained from the original $\mathrm{X}^{0} \mathrm{X}^{0}$ dams there were more than $100 \mathrm{XX}$ females and none of the $X Y$ ones. All the $X X$ daughters of $X Y$ females irrespective of the karyotypes of their progeny were included into the $X^{*} X^{0}$ group. Even if this method of classification led to any mistakes in the identification of $\mathrm{X}^{0} \mathrm{X}^{0}$ and $\mathrm{X}^{*} \mathrm{X}^{0}$ dams, these mistakes could not be considered as the cause of the registered segregation distortion in the varying lemming; on the contrary, they could but have reduced somewhat the real estimates of the distortion.

\section{RESULTS}

When considering our data, Bull and Bulmer (1981) noted that in the progeny of $X^{*} X^{0}$ females a significant excess of XY daughters was observed as compared with the expected, if transmission of sex chromosomes was equal. In the offspring of $\mathrm{XY}$ dams the proportion of $\mathrm{XY}$ daughters was also slightly increased but this increase was statistically insignificant, and Bull and Bulmer concluded that in the varying lemming segregation distortion was improbable, and, if it appeared to occur, was due to the method of classification of XX females.

The data on mating females of the three genotypes have now been rechecked and essentially supplemented. They are given in table 1 . It can be seen from this table that the sex ratio in the progenies of $X^{0} X^{0}$ and $X^{*} Y$ females and the proportion of $X Y$ daughters in $X^{*} X^{0}$ dams and $X^{*} Y$ females differ significantly (or nearly significantly) from the values expected, if sex chromosomes in males and all females segregate randomly. Only the sex ratio in the offspring of $X^{*} X^{0}$ females deviates slightly and insignificantly from the expected value, but it is not surprising: if my hypothesis on the cause of all deviations is true, the proportion of males should be affected in this group to the least extent.

The hypothesis suggest that all the departures observed result from a preferential segregation of the $Y$ chromosome in males. It is not difficult to ascertain that an excess of Y-bearing sperm must bring about deviation of both sex ratio and proportion of XY females that take place exactly in the directions they do in reality. Before accepting the hypothesis it is necessary to examine whether the deviations in question might not have been produced by a selective prenatal or early postnatal loss of the genotypes which were deficient at the time of sexing and karyotyping. If so, a correlation must exist between sex ratio and size of litter at birth and/or at weaning and between frequency of XY females and size of litter at birth and/or at 
Table 1 Sex ratio and frequency of XY daughters in progeny of females of diverse genotypes. Each of three female groups is homogenous for both characteristics of the progeny $\left(\chi^{2}=53 \cdot 64-59 \cdot 47, p=0 \cdot 19-0 \cdot 73\right)$

\begin{tabular}{|c|c|c|c|c|c|}
\hline & & & \multicolumn{3}{|c|}{ Mothers' genotype } \\
\hline & & & $\mathrm{X}^{0} \mathrm{X}^{0}$ & $X^{*} X^{0}$ & $\mathrm{X}^{*} \mathrm{Y}$ \\
\hline Number of mothers & & & 62 & 56 & 68 \\
\hline \multirow{6}{*}{ Sex ratio in progeny } & & 381 & 195 & 205 \\
\hline & Number of females & & 311 & 524 & 497 \\
\hline & \multirow[t]{4}{*}{ Proportion of males } & Expected ${ }^{*}$ & $0 \cdot 500$ & $0 \cdot 250$ & $0 \cdot 333$ \\
\hline & & Observed & 0.551 & $0 \cdot 271$ & $0 \cdot 292$ \\
\hline & & $\chi^{2}$ & $7 \cdot 08$ & $1 \cdot 72$ & $5 \cdot 31$ \\
\hline & & $p$ & 0.008 & $0 \cdot 189$ & $0 \cdot 021$ \\
\hline Number of mothers & & & 62 & 50 & 55 \\
\hline \multirow[t]{6}{*}{ Frequency of $\mathrm{XY}$ daughters } & \multicolumn{2}{|l|}{$\begin{array}{l}\text { Number of XX } \\
\text { daughters }\end{array}$} & 97 & 187 & 135 \\
\hline & \multicolumn{2}{|l|}{$\begin{array}{l}\text { Number of } \mathrm{XY} \\
\text { daughters }\end{array}$} & 0 & 131 & 165 \\
\hline & \multirow{4}{*}{$\begin{array}{l}\text { Proportion of } \mathrm{XY} \\
\text { daughters }\end{array}$} & Expected* & 0 & $0 \cdot 333$ & $0 \cdot 500$ \\
\hline & & Observed & 0 & $0 \cdot 412$ & 0.550 \\
\hline & & $\chi^{2}$ & & $8 \cdot 92$ & $3 \cdot 00$ \\
\hline & & $p$ & & 0.003 & 0.083 \\
\hline
\end{tabular}

* If no segregation distortion occurs.

the time of karyotyping. For example, a negative correlation should be expected between the size of litter and the sex ratio in offspring of $\mathrm{X}^{0} \mathrm{X}^{0}$ females, and a positive one between the same characters in the progeny of $X^{*} Y$ dams. The Spearman coefficients of the range correlation were computed for all variants. They varied from $-0 \cdot 129$ to $0 \cdot 222$ and did not differ significantly from 0 except $R_{S}=-0.251(p<0.05)$ for size of litter at the time of karyotyping and the proportion of $\mathrm{XY}$ daughters in $X^{*} X^{0}$ females. In this instance the effect of selective death might combine with that of the drive of the $\mathrm{Y}$ chromosome in males; the supposition is supported by the fact that the segregation distortion was found to be one of the highest in the variant in question, as is shown below. In any case, a single significant correlation cannot explain the biased segregation ratios in all other variants. The absence of a significant correlation between sex ratio and early postnatal mortality corroborates our previous findings (Gileva et al., 1980) demonstrating that no selective loss of either sex occurs from birth to weaning. Hence the sex ratio at weaning is practically the same as the secondary sex ratio.

To understand what kind of events might be responsible for segregation distortion in the varying lemming, a cytological analysis was undertaken. The regularity of meiotic disjunction of sex chromosomes was shown. Of the 107 secondary spermatocytes of 9 males, 54 carried the $X$ chromosome, the other contained the Y. Well-known difficulties in studying the female meiosis in mammals permitted to investigate only 18 secondary oocytes of $7 \mathrm{XY}$ females; 10 of them had the X chromosome. All the 33 secondary oocytes of 13 $\mathrm{XX}$ females possessed the $\mathrm{X}$ chromosome.

Thus, the segregation distortion in the varying lemming is most likely the result of some of $\mathrm{X}$ bearing sperm being eliminated from the competition at a time interval from the end of meiosis to fertilization. It cannot be excluded that this elimination is a consequence of certain concealed disturbance of meiosis, as it was inferred for the SD-system in Drosophila (Zimmering et al., 1970). In Aedes meiotic drive is associated with the breakage of the $\mathrm{X}$ during male meiosis (Wood, Newton, 1982).

It is not quite evident whether segregation distortion occurs in lemmings of both sexes or only in one of them. The drive of the $\mathrm{Y}$ chromosome in males seems to be undeniable: otherwise one cannot explain the bias of sex ratio in the progeny of females homozygous for $X^{0}$. The occurrence of meiotic drive in $\mathrm{X}^{*} \mathrm{X}^{0}$ and/or $\mathrm{X}^{*} \mathrm{Y}$ females is much less evident; its possibility will be considered later. It would be rational to analyse first the situation when only the Y chromosome of males is driven, while sex chromosomes in females are transmitted equally. The segregation ratio of the $\mathrm{Y}$ in males was calculated from experimental frequencies of genotypes on the basis of the inheritance pattern of sex chromosomes. Errors were computed according to the methods described by Urbach 
(1964). The following frequencies of the Y-bearing spermatozoa were obtained:

from the sex ratio in the progeny of

$$
\mathrm{X}^{0} \mathrm{X}^{0} \text { females }-0.551 \pm 0.019
$$

$\mathrm{X}^{*} \mathrm{X}^{0}$ females $-0.542 \pm 0.033$

$\mathrm{X}^{*} \mathrm{Y}$ females $-0 \cdot 589 \pm 0 \cdot 026$

from the proportion of $X Y$ daughters in

$\mathrm{X}^{*} \mathrm{X}^{0}$ females $-0.584 \pm 0.028$

$X^{*} Y$ females $-0 \cdot 550 \pm 0 \cdot 029$

Thus, all the scores of the segregation ratio of the $\mathrm{Y}$ are reasonably similar. It seems incorrect however to average them because the estimates obtained from the sex ratio in the offspring of $X^{*} X^{0}$ and $X^{*} Y$ females and those calculated from the proportion of $X Y$ daughters are not independent. It is rational therefore to consider the possible populational consequences of segregation distortion in the varying lemming for the entire range of estimates $(0 \cdot 54-0.59)$, as it is done in the next section of the paper.

Let us now refer back to the question of the possibility of meiotic drive occurring in $\mathrm{X}^{*} \mathrm{X}^{0}$ and $X^{*} Y$ females. It can be shown that if any of sex chromosomes is assumed to be driven in males, and if the strength of the drive is similar in both sexes $(0 \cdot 54-0 \cdot 59)$, the concordance between the theoretical and observed frequencies of genotypes is worse, as a rule, than when assuming meiotic drive only in males. However, the differences between the expected and the observed values are not always significant, particularly when the $X^{*}$ chromosome is regarded as driven, its segregation ratio being no more than $0 \cdot 55$. So it cannot be excluded that there is a weak segregation distortion in $\mathrm{X}^{*} \mathrm{X}^{0}$ and $\mathrm{X}^{*} \mathrm{Y}$ females of D. torquatus, but that seems hardly very probable, the more because meiotic drive in animals is usually observed only in one sex, namely in males (Zimmering et al., 1970). The next section shall therefore discuss populational implications of meiotic drive solely in males of the varying lemming.

The genetic basis of the preferential segregation of the $\mathrm{Y}$ in males is not clear. All the males mated seemed to be homogenous in this respect, but to draw a definite conclusion, more experimental data than available are required.

\section{DISCUSSION}

It might be assumed that the segregation distortion found in $D$. torquatus was too small to have any serious consequences at the population level. The consequences can be estimated using the formulae for equilibrium frequencies of female and male genotypes of $D$. torquatus written by Bull and Bulmer (1981) for an infinite panmictic population. The variables in the formulae are segregation ratio and relative fertility of the three female genotypes.

As to fertility, it was shown earlier (Gileva et al., 1982) that the increased ovulation rate led to a compensation of the loss of a quarter of zygotes in $\mathrm{X}^{*} \mathrm{Y}$ females. It was reported that in D. t. chionopaes $\mathrm{X}^{*} \mathrm{X}^{0}$ females displayed a higher fertility, $\mathrm{X}^{0} \mathrm{X}^{0}$ and $\mathrm{X}^{*} \mathrm{Y}$ females being equal in this relation. Results of further investigations on both $D$. $t$. torquatus and D. t. chionopaes combined with all the previous data are presented here. The XX females are classified according to the genotypes of both their mothers and their progeny. The mean reproductive output (mean number of offspring weaned per month per female) and found to be $2 \cdot 09 \pm 0 \cdot 19$, $2 \cdot 11 \pm 0 \cdot 18$, and $1 \cdot 82 \pm 0 \cdot 16$ for $\mathrm{X}^{0} \mathrm{X}^{0}, \mathrm{X}^{*} \mathrm{X}^{0}$ and $\mathrm{X}^{*} \mathrm{Y}$ females, respectively $(F=2 \cdot 44, p>0 \cdot 05)$. The differences are not significant, but a certain tendency towards a reduced fertility of $\mathrm{X}^{*} \mathrm{Y}$ females is to be noted. The data on the reproductive output are based on experiments with animals comprising a little less than half of the whole of the laboratory colonies. So estimating the genotype frequencies expected in the colonies it seems rational to examine what are their values with real fertilities observed in experiments ard not only when the three female genotypes are equally fertile. When calculating frequencies expected in natural populations it is more correct to use equal fecundities of the three types of females.

If the relative fertilities of $X^{0} X^{0}, X^{*} X^{0}$ and $X^{*} Y$ females are, as in the experiments mentioned above, that is $1 \cdot 00: 1 \cdot 01: 0.87$, and if the segregation in females is random while the segregation ratio of the $\mathrm{Y}$ in males is $0.54-0.59$, the expected sex ratio in the colonies should be $0.43-0.40$ and the expected proportion of XY females should be $0 \cdot 25-0 \cdot 39$. If no segregation distortion occurs in males, the estimates are expected to be 0.45 and $0 \cdot 13$, respectively. In the case of equal fecundity of the three female genotypes, the predicted values of the sex ratio and the proportion of XY females would be equal to $0 \cdot 40-0 \cdot 38$ and $0 \cdot 31-0 \cdot 43$, respectively. In the absence of meiotic drive these estimates are 0.42 and 0.20 , respectively.

In fact, in our colonies (D. t. torquatus and $D$. $t$. chionopaes combined) the sex ratio was 0.37 $(n=3475)$ and the proportion of the XY karyotype among females was $0 \cdot 36(n=1320)$. These scores differ significantly from the theoretical frequencies given above for the case of equal transmission of heterochromosomes in both sexes $\left(\chi^{2}=38.91\right.$ and 
$210 \cdot 80$, respectively), but they are within the limits determined for the preferential segregation of the Y-bearing sperm $(0 \cdot 54-0 \cdot 59)$, except that the experimental sex ratio was slightly less than the lowest theoretical estimate predicted. However, the difference is insignificant $\left(\chi^{2}=2 \cdot 21\right)$.

One can scarcely expect to find a good conformity between theoretical estimates and real frequencies of genotypes in natural populations. In the wild, sex ratio is noticeably affected by demographic processes. Its registered scores also depend on the methods of trapping. In what way the proportion of XY karyotype in females may be influenced is less evident. Not much is known about the non-reproductive components of the relative fitness of $\mathrm{XX}$ and $\mathrm{XY}$ females. Apparently they are not equal to 0 . A weak but significant negative correlation between the size of litter and the proportion of $\mathrm{XY}$ daughters at the time of karyotyping in $X^{*} X^{0}$ females suggests a relatively higher early postnatal loss of XX daughters to that of the XY ones. Furthermore, the reared XY females possess on average a larger body size than the $\mathrm{XX}$ ones, and if so in the wild, $\mathrm{XY}$ females may have a selective advantage in the arctic tundra which is the native habitat of the varying lemming. It has to be noted that according to the theoretical analysis of Bull and Bulmer (1981) the equilibrium frequency of $\mathrm{X}^{*} \mathrm{Y}$ genotype is essentially more sensitive to segregation distortion than the sex ratio is. The experimental data on the captive lemmings are consistent with the theory. So one can think that a more adequate indicator of the occurrence of meiotic drive in the wild is the proportion of $X Y$ females rather than the sex ratio.

Now let us consider the data on natural populations. As expected, the sex ratio varied noticeably in diverse populations of Dicrostonyx, i.e. 0.50 (Manning, 1954; Fuller et al., 1975), 0.45 (Chernyavsky, and Kiryutschenko, 1979), and 0.40 (Dunaeva, 1978). In the latter two cases deviations from 0.5 were statistically significant, and as to the former case a significant deficit of males among juvenile animals was observed.

The frequency of XY females was investigated in 8 palaearctic populations of the varying lemming. They were found in all the localities except one region from where only one female was karyotyped. The number of animals studied in each population was not big, so all the data are combined. Among 56 females karyotyped, $24(0 \cdot 43)$ possessed an $X Y$ constitution. An excess of $X Y$ karyotype as compared to the theoretical frequency for $1: 1$ segregation $(0 \cdot 2)$ is highly significant $\left(\chi^{2}=\right.$ $48 \cdot 29)$.
Thus, the situation in natural populations at least does not contradict the experimental results suggesting the existence of meiotic drive in the varying lemming. It is reasonable to believe that meiotic drive is responsible to a large extent for the excess of the $X^{*} Y$ genotype among females of $D$. torquatus in the wild. Theoretically the frequency of $\mathrm{X}^{*} \mathrm{X}^{0}$ genotype must also be increased by the meiotic drive in males. Unfortunately, difficulties connected with distinguishing between $\mathrm{X}^{*} \mathrm{X}^{0}$ and $\mathrm{X}^{0} \mathrm{X}^{0}$ females did not permit to examine this prediction in our colonies.

It is of interest that the same meiotic drive of the $\mathrm{Y}$ in males can cause a local surplus of males, if the $\mathrm{X}^{*}$ chromosome is lost in some subpopulation and only $\mathrm{X}^{0} \mathrm{X}^{0}$ females reproduce. Perhaps that was the case with the experiments performed by Jarrell on Alascan varying lemmings. He reported (1985) that after 9 generations of laboratory breeding the sex ratio in the progeny of XX females had become $0 \cdot 67$. However, such a happening must be rare in the wild, because even a moderate segregation distortion, such as in the two subspecies studied, is sufficient for a marked increase in the frequency of the $X^{*}$ in a population.

Most probably meiotic drive is one of the forces maintaining the $\mathrm{X}^{*}$ chromosome and hence females with a male karyotype in the populations of the varying lemming. Moreover, it may be assumed that meiotic drive has contributed to the survival and the spread of a newly arisen $X^{*}$ mutation, provided the drive had occurred before the mutational event. There is some reason to believe that segregation distortion in the sex chromosome system had already been taking place in ancestors of recent Microtinae (subfamily to which Dicrostonyx belongs). This hypothesis is corroborated by the fact that meiotic drive is apparently responsible for the significant deviations of the secondary sex ratio from $1: 1$ which have been observed in some other microtines of our laboratory stocks. A preliminary analysis showed that the deviations did not result from the selective embryonal mortality. Moderate segregation distortion of sex chromosomes is likely to occur in other mammals. In particular, such a mechanism is strongly suspected in the human in relation to the well-known excess of males at the time of conception and at birth (Zimmering et al., 1970; Harrison et al., 1977).

To sum up, the case of $D$. torquatus demonstrates, on one hand, the necessity of a conspicuous and sensitive marker for revealing a moderate meiotic drive (the drive in the varying lemming would hardly be discovered, if it were not for the $\mathrm{XY}$ females being found earlier), and, on the other 
hand, the possible significance of a relatively weak segregation distortion in some populational and evolutionary processes.

Acknowledgement I would like to thank Dr N. V. Glotov for his valuable consultation and Mrs C. C. Potapenko for her assistance in preparing the manuscript.

\section{REFERENCES}

BULL, J. J. AND BULMER, M. G. 1981. The evolution of XY females in mammals. Heredity, 47, 347-365.

CAROTHERS, A. D. 1980. Population dynamics and the evolution of sex determination in lemmings. Genet. Res., 36, 199-209.

CHERNYAVSKY, F. B. AND KIRYUTSCHENKO, S. P. 1979. Breeding and mortality of the varying lemming, Dicrostonyx torquatus on the Vrangell Island. In Ecology of Voles and Shrews in Northeastern Siberia, Vladivostok, pp. 3-24 (In Russian).

DUNAEVA, T. N. 1978. On the lemming ecology in Northeastern Yakutia. Bulletin of the Moscow Naturalists' Society, 83, 18-27 (In Russian).

FREDGA, K., GROPP, A., WINKING, H. AND FRANK, F. 1976. Fertile XX- and XY-type females in the wood lemming. Myopus schisticolor. Nature, 261, 225-228.

FULLER, W. A., MARTELL, A. M., SMITH, R. F. C. AND SPELLER, S. W. 1975. High-arctic lemming (Dicrostonyx groenlandicus). II. Demography. Canad. J. Zool., 53, 867-878.

GILEVA, E. A. 1980. Chromosomal diversity and an aberrant genetic system of sex determination in the arctic lemming, Dicrostonyx torquatus Pallas (1779), Genetica, 52/53, 99103.

GILEVA, E. A. 1983. A contrasted pattern of chromosome evolution in two genera of lemmings, Lemmus and Dicrostonyx. Genetica, 60, 173-179.

GILEVA, E. A., BENENSON, I. E., POKROVSKY, A. V. AND LOBANOVA, N. A. 1980. An analysis of aberrant sex ratio and postnatal mortality in progeny of the varying lemming, Dicrostonyx torquatus. Ekologiya, 6, 46-52 (In Russian).
GILEVA, E. A., BENENSON, I. E., KONOPISTSEVA, L. A., PUCH. KOV, V. F. AND MAKARANETS, I. A. 1982. XO females in the varying lemming, Dicrostonyx torquatus: reproductive performance and its evolutionary significance. Evolution, $36,601-609$.

GILeVA, E. A. AND ChebotAR, N. A. 1979. Fertile XO males and females in the varying lemming, Dicrostonyx torquatus Pall. (1779). Heredity, 42, 67-77.

HARRISON, G. A., WEINER, J. S., TAUNER, J. M., BARNICOT, N. A. AND REYNOLDS, v. 1977. Human Biology, Oxford University Press, Oxford.

JARRELL, G. H. 1985. Male-biased reproduction in collared lemming (Dicrostonyx). Abstracts of Papers and Posters. Fourth International Theriological Congress, Edmonton, 1985. Abstract No. 0321.

KOZLOVSKY, A. I. 1974. Karyotype differentiation in northeastern subspecies of the varying lemming. Proceedings of the Academy of Sciences of the USSR, 219, 981-984 (In Russian).

Levontin, R. C. 1967. Population genetics. Ann. Rev. Genet., $1,37-70$.

MANNING, T. H. 1954. Remarks on the reproduction, sex ratio and life expectancy of the varying lemming, Dicrostonyx torquatus in nature and captivity. Arctic, 7, 36-38.

RAUSCH, R. L. AND RAUSCH, V. R. 1972. Observation on chromosomes of Dicrostonyx torquatus stevensoni Nelson and chromosomal diversity in varying lemmings. $Z$. Säugetierkunde, 37, 372-384.

SANDLER, L. R. G. AND NOVITSKI, E. 1957. Meiotic drive as an evolutionary force. Amer. Natur., 91, 105-110.

SNYDER, L. R. C. 1983. Selection components affecting hemoglobin in Peromyscus maniculatis: a re-evaluation. Evolution, 37, 639-642.

URBACH, V. U. 1964. The Biometrical Methods. Nauka, Moscow (In Russian).

WHITE, M. J. D. 1978. Chromosomes, 6th ed. Chapman and Hall, London.

WOOD, R. J. AND NEWTON, M. E. 1982. Meiotic drive and sex ratio distortion in mosquitoes. In Recent Developments in the Genetics of Insect Disease Vectors, Stripes Publishing Company, pp. 130-152.

ZIMMERING, S., SANDLER, L. AND NICOLETTI, B. 1970 Mechanisms of meiotic drive. Ann. Rev. Genet., 4, 409-436. 